\title{
A latent structural equation model of protective behaviors and pressure ulcer outcomes among people living with spinal cord injury
}

\author{
C Li, ND DiPiro and J Krause
}

\section{Study design: Cross-sectional.}

Objective: To develop a latent structural model to demonstrate the relationship between factor structures of protective health behaviors and pressure ulcer ( $\mathrm{PrU}$ ) outcomes among participants with spinal cord injury (SCI).

Setting: Data were collected at a large specialty hospital and analyzed at a medical university in the Southeastern USA.

Methods: A total of 1871 participants with traumatic SCl of at least 1 year duration were included. A latent PrU variable was measured by four observable PrU-related outcomes. Latent variable structural equation modeling was performed to assess the relationship between latent protective behavior (fitness and productive activities) and latent PrU outcome. Several exogenous variables were included: sex, age, race, marital status, injury severity and years since injury.

Results: The protective behavior dimension had a significant direct effect on the latent $\operatorname{PrU}$ (direct effect $=-0.275, P<0.01$ ). All direct relationships between protective behavior dimension and healthy behaviors were also significant $\left(r_{\text {fit }}=0.899\right.$ and $r_{\text {productive activity }}=0.568$ ). Relationships between the latent PrU and fitness (indirect effect $=-0.247$ ) and productive activities (indirect effect $=-0.156$ ) were mediated through the protective behavior dimension. Participants who were African American, had higher injury levels, and had longer time since SCI were more likely to have worse PrU outcomes.

Conclusions: The overall findings of this study suggest the need to enhance healthy behaviors to prevent adverse PrU outcomes, especially among people who are African American, have longer time since SCl and have higher level of $\mathrm{SCl}$.

Spinal Cord (2017) 55, 135-140; doi:10.1038/sc.2016.166; published online 29 November 2016

\section{INTRODUCTION}

Spinal cord injury (SCI) results in a number of physiologic and functional changes placing individuals at heightened risk for the development of secondary health conditions, such as pressure ulcers (PrU). A PrU is defined as injury to the skin or underlying tissue, commonly over a bony prominence, as a result of pressure and/or shear. ${ }^{1}$ Roughly $32-48 \%$ of persons with chronic SCI report having a $\mathrm{PrU}$ in the past year, ${ }^{2-7}$ and $16-24 \%$ report having a $\mathrm{PrU}$ at any given time. $^{2-4,6,7}$ Evidence suggests the prevalence of PrU has increased in recent years. ${ }^{8}$ Considerable research has focused on the identification of risk factors, prevention and treatment of $\mathrm{PrU}$; however, $\mathrm{PrU}$ remain one of the most prevalent and devastating sequelae of SCI, with costly complications and hospitalizations in common. ${ }^{9-15}$

The risk of $\operatorname{PrU}$ is multifactorial. A substantial number of systematic reviews have addressed the risk factors ${ }^{10,11,14,16,17}$ as well as prevention and treatment of PrU. ${ }^{13,15,18,19}$ Several biographic and injury factors have been associated with PrU outcomes, including gender, $6,7,11$ race/ethnicity, ${ }^{4,6,7}$ age at injury, ${ }^{10}$ time since injury ${ }^{5-7,10}$ and severity of injury. ${ }^{4,6,7} \mathrm{~A}$ recent review by Gelis et al. ${ }^{11}$ examined PrU risk factors in chronic SCI. The authors identified 40 risk factors that were classified as socio-demographic, neurological factors, clinical, functional, behavioral, psychological or protective factors. The level of evidence was highest for socio-demographic and neurological risk factors and low for behavioral factors. Few studies have assessed protective health behaviors and PrU outcomes. Studies by Krause et al. ${ }^{2,3,5}$ have found that healthy lifestyle, exercise, diet, fitness level, increased hours out of bed and increased days out of house are protective factors of PrU outcomes in individuals with chronic SCI.

Although an abundance of research has focused on PrU after SCI, studies have primarily focused on single observable factors rather than the impact of multiple risk or protective factors on PrU outcomes. In this study, we are interested in more fully utilizing predictive models to evaluate the extent to which various protective health behaviors as clusters influence $\mathrm{PrU}$ outcomes in individuals with chronic SCI. Although individual protective behaviors are manifest, or observable, variables, model building requires identification of clusters of behaviors that may form underlying latent dimensions representing broader constructs not tied to specific observations.

Our purpose was to model the relationship between latent $\operatorname{PrU}$ and latent protective health behaviors using structural equation modeling (SEM). Four PrU outcomes were examined, including the number of $\mathrm{PrU}$ in the past year, the number of weeks in the past year that $\operatorname{PrU}$ resulted in reduced sitting time, the number of times hospitalized for a $\mathrm{PrU}$ and current PrU. Building on findings from previous research, 2,3,5 the protective factors we examined included the following: fitness level, exercise, diet, hours per week in home maintenance activities, 
volunteer work and recreational activities. We identified multiple manifest endogenous variables (for example, fitness, exercise, diet, home maintenance, volunteer and recreational activities) that define protective factors and linked latent $\mathrm{PrU}$ to key exogenous predictors (for example, sex, race, age, marital status, years since SCI and injury severity) that have been widely used in the literature.

\section{MATERIALS AND METHODS}

\section{Study design and participants}

This was a cross-sectional study nested within a prospective cohort study that was initiated in 1997-1998 at a large specialty hospital in the Southeastern USA. The inclusion criteria of this study were as follows: (1) traumatic SCI, (2) at least 1 year since SCI onset, (3) 18 years of age or older and (4) some residual deficits from the SCI (not complete recovery, AIS A-D). There were two study cohorts used in the current analysis, the first of which was enrolled at baseline in 1997-1998 and the second of which was first enrolled in 2007-2009. Both cohorts were recruited for a follow-up in 2011-2014, from which the data were analyzed for the current study.

There were a total of 1871 participants in the current study, 625 from cohort 1 and 1246 from cohort 2. Figure 1 summarizes the response patterns over time. For cohort 1, out of 1839 potential eligible participants, 1386 responded to the initial study in $1987-1998$ (response rate $=75.4 \%$ ). Ten years later in 2007-2009, 863 participants again completed materials, 329 were deceased and 194 were lost to follow-up (response rate $=81.6 \%$ ). At the 2011-2014 follow-up, 611 of the 863 participants in cohort 1 again responded (adjusted-response rate $=81.1 \%$ ). In addition, 14 participants who were nonrespondents at time 2 responded at time 3 .

The second cohort was recruited in 2007-2009 from the same specialty hospital. Out of 2243 potential participants, 1684 responded (response rate $=$ 75.1\%). In 2011-2014, 1179 participants in cohort 2 responded (response rate adjusted for mortality $=76.0 \%$ ). In addition, 67 of 84 participants who were non-respondents during the 2007-2009 data collection responded in 2011-2014. These participants were selected because they had participated in a different study and were known to have viable contact information.

Health 15-Year Flow Chart

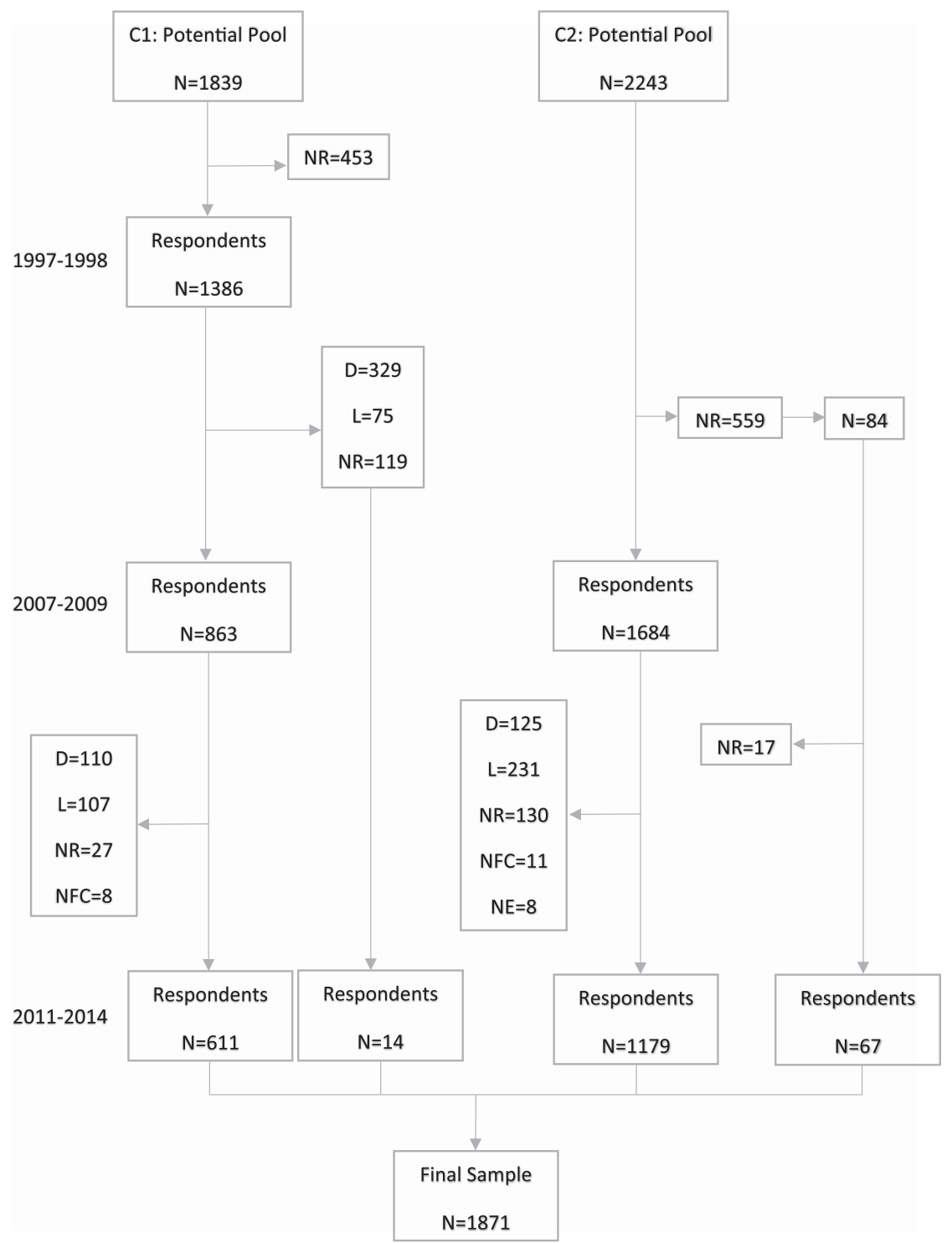

Figure 1 Response patterns over time. A full color version of this figure is available at the Spinal Cord journal online. 


\section{Procedures}

Approval from the Institutional Review Board was obtained before initiating data collection. The same general procedures were followed at baseline and at subsequent follow-ups. Cover letters were sent to prospective participants 4-6 weeks before mailing the self-reported assessment. A second mailing was sent out to all non-respondents within 2 months of the initial mailing. Non-respondents after the second mailing were contacted by phone, and a third mailing was sent if the non-respondents verbally stated they wanted to participate and requested additional materials. Participants were offered $\$ 50$ on completion and return of the self-report assessment.

\section{Measures}

Participants completed a composite instrument comprised of multiple measures and some items that were developed during the baseline component of the study (SCI Health Assessment). Socio-demographic characteristics included age, sex, race (White, African American and other races) and marital status (married vs others). Injury-related variables included years since SCI and injury severity, which was based on a combination of neurologic level and ambulatory status using a scale previously reported in the literature related to mortality. ${ }^{20}$ The first category includes all ambulatory participants, regardless of neurologic level, whereas the non-ambulatory participants were broken down into the following three groups based on neurologic level: C1-4, C5-8 and non-cervical.

Fitness, exercise, diet and several health-productive activities were measured by the SCI Health Assessment, ${ }^{21}$ which was designed to identify behavioral and secondary condition domains after SCI. Four items were used to measure fitness, exercise and diet. The first item measured overall fitness on a 5-point rating scale (poor, fair, good, very good and excellent). Another two exerciserelated items were in somewhat different formats. A 5-point rating scale (much less, less, about the same, more and much more) was used for the amount of exercise comparing to others with similar SCI. A 6-category scale (rarely, once per month, 2-3 times per month, 1-2 times per week, 3-4 times per week and 5 or more times per week) was grouped for the frequency of planned exercise. Diet was measured by a 5-category scale (poor, fair, good, very good and excellent) designed to access how healthy is the diet in general.

Several health-productive activities were included based on a series of questions from the Craig Handicap Assessment and Reporting Technique (CHART). ${ }^{22}$ The CHART is a 27 -question assessment that objectively measures the degree to which impairments and disability affect five dimensions of handicap, as defined by the World Health Organization. We selected three items from the CHART occupational dimension asking about hours per week of performing certain behaviors to maintain better health status. The items included 'How many hours per week do you spend in (1) home maintenance activities such as gardening, house repairs or home improvement?, (2) ongoing volunteer work for an organization? and (3) recreational activities such as sports, exercise, play cards or going to movies (watching TV and listening to the radio are not included)?'.

The main outcome (PrU) was defined as 'open sores in pressure areas, such as your tailbone, ischium, heel, elbows. They are usually caused by pressure but may also be caused by friction or shearing (rubbing), moisture, burns or falls.' ${ }^{3}$ Latent PrU was measured by four self-reported questions. They were as follows: (1) 'Do you currently have a pressure/skin sore?'; (2) 'All totaled, how many different open pressure sores have you had in the past year? (including sores you have right now)'; (3) 'Approximately how many weeks in the past year were you forced to reduce your sitting time as a result of these sores?'; and (4) 'How many times (if any) have you been hospitalized for a pressure/skin sore in the past year?'.

\section{Statistical analyses}

Means and standard deviations were calculated for continuous variables, and frequencies and percentages were generated for categorical variables. Pearson and Spearman correlations were computed to investigate correlations among fitness, exercise, diet and productive activities developed based on previous studies. ${ }^{23}$ Level of correlation was determined as follows: weak at $<0.3$, moderate between 0.3 and 0.5 and strong at $>0.5$.

We used SEM to examine the hypothesized model based on the bi-dimensional behavioral model ${ }^{24}$ and a replication of an earlier research factor analysis. ${ }^{23}$ Two latent protective behavior indicators (fit and productive activity) were measured by corresponding observed variables and further linked with a higher dimension classified as the protective behavior dimension. The latent fit variable was measured by fitness, amount of exercise compared with others with similar SCI, frequency of planned exercise and diet. Hours per week doing home maintenance activities, volunteer work and recreational activities were used to measure the latent productive activity variable. The latent $\operatorname{PrU}$, predicted by the number of $\operatorname{PrU}$ in the past year, the number of weeks in the past year that PrU resulted in reduced sitting time, the number of times hospitalized for a $\operatorname{PrU}$ and current $\operatorname{PrU}$ status, was treated as the outcome in the modeling in relation to the protective behavior dimension and also several exogenous variables including sex, age, race, marital status, years since SCI and injury severity. Multiple adequacy of fit criteria were used to assess the model fit of the hypothesized model: chi-square, comparative fit index, Tucker Lewis index and root mean square of approximation. The comparative fit index and Tucker Lewis index with values of $>0.95$ indicate a good match between the data and the hypothesized model. A root mean square of approximation of $<0.08$ suggests minimized rates of type I and type II error.

Descriptive analyses were conducted by SAS (Version 9.4, SAS Institute, Cary, NC, USA). M-plus (Version 7.4, Muthen \& Muthen, Los Angeles, CA, USA) was used to assess all correlations and SEM. The standard of significance was set at $P<0.05$.

\section{Statement of ethics}

We certify that all applicable institutional and governmental regulations concerning the ethical use of human volunteer were followed during the course of this research.

\section{RESULTS}

Study participants were mainly male $(74.5 \%)$ and White $(74.4 \%)$ and averaged 48.3 (s.d. $=13.3$ ) years of age. $41.5 \%$ were married. The average years since injury was 15.9 (s.d. =10.1), and $34.9 \%$ had non-cervical non-ambulatory injury, followed by ambulatory injury (29.7\%), C5-8 non-ambulatory injury (25.5\%) and C1-4 nonambulatory injury (9.9\%). Participant characteristics are summarized in Table 1. Correlations among fitness, exercise, diet and productive activities are provided in Table 2 .

The model fit indices of the hypothesized SEM model were very good: $\chi^{2}=481.110, \mathrm{df}=101, \chi^{2} / \mathrm{df}=4.76, \quad P<0.0001$, root mean square of approximation $=0.046$, comparative fit index $=0.959$, Tucker Lewis index $(\mathrm{TLI})=0.951$. The protective behavior dimension had a significant direct effect on the latent $\operatorname{PrU}$ (direct effect $=-0.275$, $P<0.01)$. All direct relationships between the protective behavior dimension and healthy behaviors were also significant $\left(r_{\text {fit }}=0.899\right.$ and $r_{\text {productive activity }}=0.568$ ). The relationships between the latent $\operatorname{PrU}$ and fitness, exercise and diet (indirect effect $=-0.275 \times 0.899=-0.247$ ), and productive activities (indirect effect $=-0.275 \times 0.568=-0.156$ ) were mediated through the protective behavior dimension (Figure 2).

With regard to the exogenous variables, race, years since SCI and injury severity were significantly related to the latent PrU (Table 3). To evaluate the within-group difference between categorical exogenous variables ( $>2$ categories) and the latent $\operatorname{PrU}$, we created dummy variables for race ( $\mathrm{ref}=$ White) and injury severity ( $\mathrm{ref}=$ ambulatory), and re-ran the SEM model demonstrated in Figure 2. Results are summarized in Table 3. The non-ambulatory participants were more likely to have worse $\mathrm{PrU}$ consequences than ambulatory participants. The more severe the SCI, the worse the PrU ( $r_{\text {non-ambulatory:C1-C4 vs ambulatory }}=0.450, r_{\text {non-ambulatory:C5-C } 8 \text { vs ambulatory }}$ $=0.361, r_{\text {non-ambulatory: non-cervical vs ambulatory }}=0.232$ ). Years since SCI showed a marginal significant positive association with $\mathrm{PrU}$ controlling for chronological age (that is, greater time as SCI predicted more consequences of $\mathrm{PrU}$ ). African American participants had a significant positive relationship with the latent $\operatorname{PrU}$ comparing with White 
Table 1 Demographic characteristics

\begin{tabular}{|c|c|c|}
\hline & $\mathrm{N}$ & $\%$ \\
\hline \multicolumn{3}{|l|}{ Sex } \\
\hline Male & 1394 & 74.5 \\
\hline Female & 447 & 25.5 \\
\hline \multicolumn{3}{|l|}{ Race } \\
\hline White & 1386 & 74.4 \\
\hline Black & 406 & 21.8 \\
\hline Others & 71 & 3.8 \\
\hline \multicolumn{3}{|l|}{ Marital status } \\
\hline Married & 770 & 41.5 \\
\hline Single & 1084 & 58.5 \\
\hline \multicolumn{3}{|l|}{ Chronological age } \\
\hline$<40$ & 515 & 27.5 \\
\hline $40-49$ & 491 & 26.2 \\
\hline $50-59$ & 459 & 24.5 \\
\hline $60-69$ & 300 & 16 \\
\hline $70+$ & 106 & 5.7 \\
\hline \multicolumn{3}{|l|}{ Years post injury } \\
\hline$<20$ & 1296 & 69.3 \\
\hline $20-29$ & 402 & 21.5 \\
\hline 30-39 & 119 & 6.4 \\
\hline $40-49$ & 41 & 2.2 \\
\hline $50+$ & 11 & 0.6 \\
\hline \multicolumn{3}{|l|}{ Injury severity } \\
\hline Non-ambulatory: C1-C4 & 183 & 9.9 \\
\hline Non-ambulatory: C5-C8 & 469 & 25.5 \\
\hline Non-ambulatory: non-cervical & 643 & 34.9 \\
\hline Ambulatory & 547 & 29.7 \\
\hline
\end{tabular}

Table 2 Correlation matrix

\begin{tabular}{|c|c|c|c|c|c|c|c|}
\hline & 1 & 2 & 3 & 4 & 5 & 6 & 7 \\
\hline 1. Fitness & - & & & & & & \\
\hline 2. Exercise & $0.40 * *$ & - & & & & & \\
\hline 3. Planned exercise & $0.37 * *$ & $0.37 * *$ & - & & & & \\
\hline 4. Diet & $0.37 * *$ & 0.27 ** & $0.29 * *$ & - & & & \\
\hline $\begin{array}{l}\text { 5. Home mainte- } \\
\text { nance activities }\end{array}$ & $0.16^{* *}$ & $0.16^{* *}$ & $0.15^{* *}$ & $0.06^{* *}$ & - & & \\
\hline 6. Volunteer work & $0.10 * *$ & $0.07 * *$ & $0.09 * *$ & $0.08 * *$ & $0.14^{* *}$ & - & \\
\hline $\begin{array}{l}\text { 7. Recreational } \\
\text { activities }\end{array}$ & 0.27 ** & $0.24^{* *}$ & $0.35^{* *}$ & $0.14^{* *}$ & $0.25^{* *}$ & $0.16^{* *}$ & - \\
\hline
\end{tabular}

participants $(r=0.096)$. Sex, marital status and chronological age were not significantly associated with the latent PrU.

\section{DISCUSSION}

This study evaluated the relationship between latent protective behavior and PrU using SEM. We found that the latent PrU was negatively associated with the latent protective health behavior predicted by fitness, exercise, diet, hours per week in home maintenance activities, volunteer work and recreational activities.
Participants who were African American, had higher injury levels and had longer time since SCI were more likely to have worse PrU outcomes.

It is not a surprise to find that the latent protective health behavior had a significant negative effect on the latent $\operatorname{PrU}$, which is consistent with findings from previous studies. Krause et al. ${ }^{2,3,5}$ reported that healthy behaviors, such as maintaining normal weight, returning to a work or family role and refraining from smoking, alcohol or drug abuse, were strongly associated with reduced risk of PrU. However, all these studies used single observable health behaviors and $\operatorname{PrU}$ outcomes. Instead, we had the opportunity to create clusters (a latent dimension) of both protective behaviors and PrU outcomes that can represent broader constructs not limited to certain health behaviors and PrU outcomes.

Furthermore, there were significant associations of the second set of endogenous items related to more general participation. Therefore, it was not simply presence of those behaviors that are intended to be protective of health, but also more global aspects of participation. As the data are cross-sectional, there is no evidence of cause and effect, and it is equally plausible that the presence of PrU led to diminished participation. This is an empirical question for future research.

Another contribution to the literature of this study is to provide additional evidence that race, years post SCI onset and severity of SCI are associated with the PrU outcomes. African Americans have been reported to be at increased risk for PrU by Chen et al. ${ }^{8,25}$ possibly due to lack of financial and educational resources. ${ }^{6}$ The more severe the SCI, the more motor impairment and mobility limitation, which makes it more difficult for people to change positions to reduce the pressure on the skin. Several studies ${ }^{3,5}$ also found that years since SCI had a marginal effect on PrU outcomes, which is similar to our findings. The skin composition and function deteriorate over time, which makes the skin more vulnerable to sustained pressure, friction and shear.

\section{Design considerations: limitations and strengths}

Like most research, this study has several limitations. First, all study participants were recruited from one rehabilitation hospital that limits the generalizability of our research findings. Second, all data analyzed in this study were measured by self-reported assessment, which made our findings subject to recall bias. Third, the data are cross-sectional and therefore cannot be taken as causal, even though SEM is designed to confirm conceptual models with cross-sectional data. Fourth, our findings are restricted to protective behaviors and, therefore, do not address the importance of risk behaviors, such as cigarette smoking or alcohol use. Ultimately, the goal of modeling will be to incorporate risk as well as protective behaviors. Our preliminary attempts to merge both sets of protective and risk behaviors were unsuccessful, so we have chosen the approach of independent analyses of each set, although building larger data sets over time that are better suited for an even larger number of variables. Moreover, we do not have data on the localization of the $\operatorname{PrU}$, and there may be differences in the extent to which predictive factors may relate to specific locations and types of PrU. This cannot be determined from the current study. Similarly, pressure relief techniques and the types of equipment used may also affect the probability of $\operatorname{PrU}$, but this also cannot be determined from the study data. Lastly, it will be important to validate the model with additional participant cohorts.

There are also several study strengths. To the best of our knowledge, this is the first study to evaluate the association between latent protective behavior and $\operatorname{PrU}$ outcomes using SEM. The latent approach allowed us to aggregate multiple observable indicators to a 


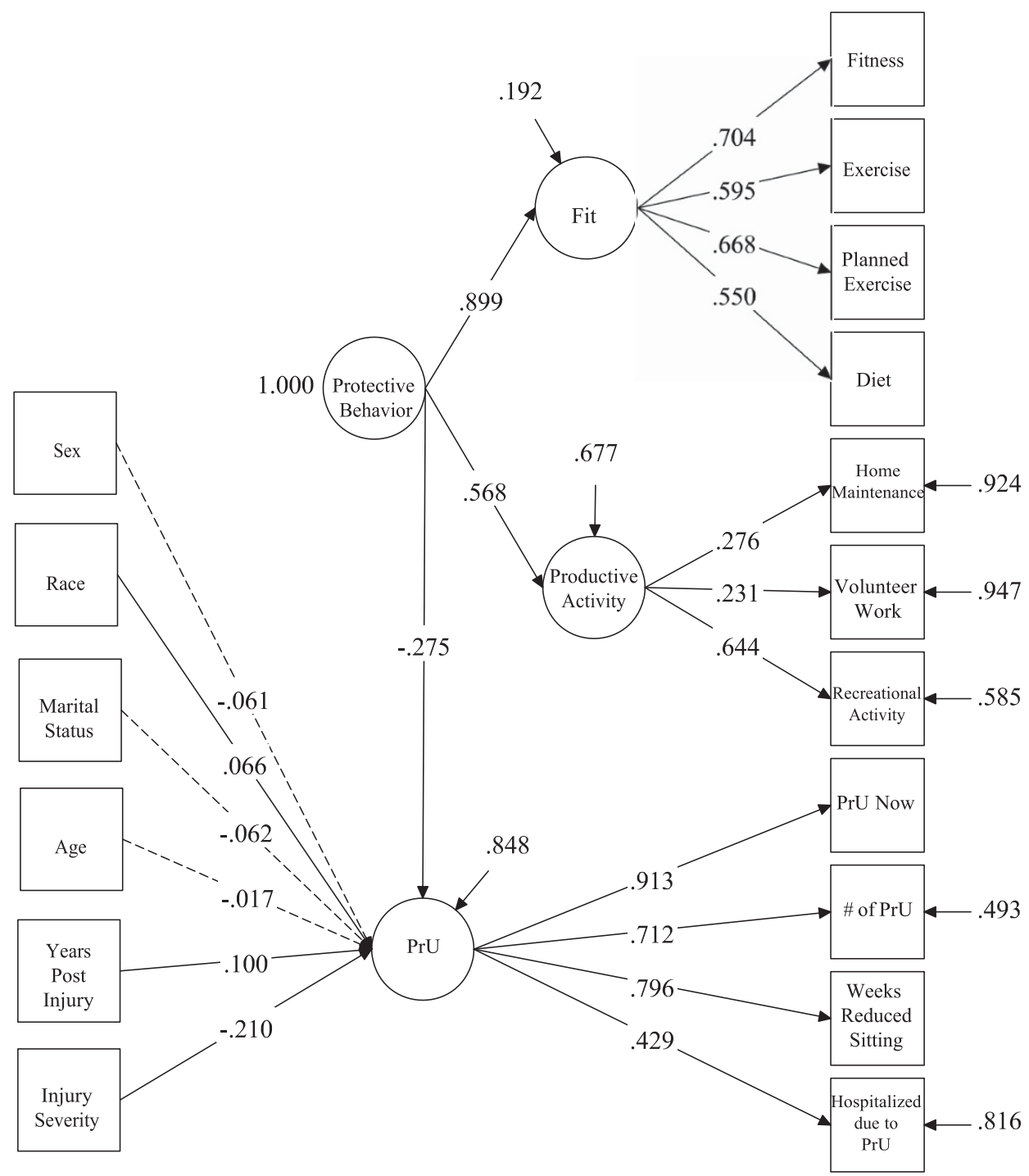

Note: A solid line indicates a significant effect and a dashed line indicates a non-significant effect.

Figure 2 Structural equation model.

Table 3 Path coefficients from the hypothesized structural equation model

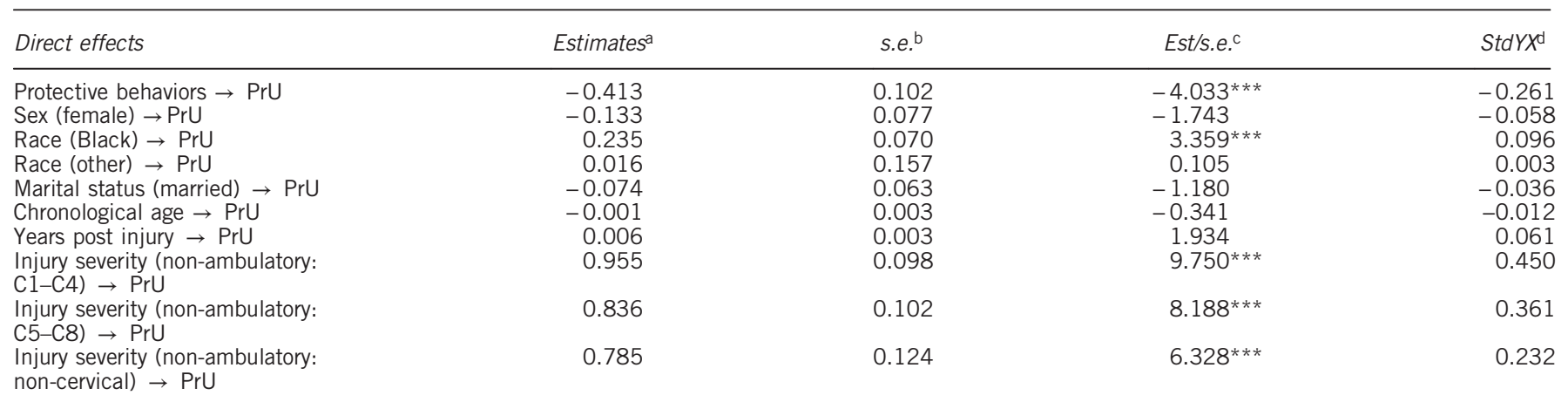

aModel estimated value for each parameter.

bStandard errors of the parameter estimates.

'Value of the parameter estimate divided by the standard error ( $t$-value).

Uses the variances of the continuous latent variables and of the background and outcome variables for standardization (standardized regression coefficient).

Values $>1.96$ are statistically significant at ${ }^{*} P<0.05,>2.58$ are significant at ${ }^{* *} P<0.01$ and $>3.29$ are significant at ${ }^{* * *} P<0.001$ 
single latent variable that was more predictive of either protective behaviors or PrU outcomes. In addition, our study recruited a large number of participants with extensive years after SCI, which granted us sufficient statistical power to test our hypothesis. We also linked some exogenous variables with the latent $\operatorname{PrU}$ to better examine the demographic (sex, age, race and marital status) and injury-related (years since SCI and injury severity) differences in terms of PrU outcomes.

\section{Future research}

Developing a protective health behavior dimension, consistent with the bi-dimensional behavioral model, ${ }^{24}$ will lead to a more comprehensive understanding of risk of PrU. Future studies are needed to test the relationship between latent risk behaviors and PrU outcomes using a similar structural approach. We then will have a better understanding of the influence of health behaviors (both risk and protective) on PrU in terms of the theoretical risk and prevention model. ${ }^{24,26}$

\section{CONCLUSION}

Our study proposed a valid latent structural model of protective behaviors and PrU outcomes. This study suggests the need to enhance healthy behaviors to prevent adverse PrU outcomes, especially among people who are African American, have longer time as SCI and have higher level of SCI.

\section{DATA ARCHIVING}

There were no data to deposit.

\section{CONFLICT OF INTEREST}

The authors declare no conflict of interest.

\section{ACKNOWLEDGEMENTS}

The contents of this publication were developed under grants from the US Department of Health and Human Services Administration for Community Living, NIDILRR grant number 90RT5003. However, those contents do not necessarily represent the policy of the Department of Health and Human Services, and you should not assume endorsement by the Federal Government.

1 Black J, Baharestani M, Cuddigan J, Dorner B, Edsberg L, Langemo D et al. National Pressure Ulcer Advisory Panel's updated pressure ulcer staging system. Dermatol Nurs 2007: 19: 343-349.

2 Krause JS, Vines CL, Farley TL, Sniezek J, Coker J. An exploratory study of pressure ulcers after spinal cord injury: relationship to protective behaviors and risk factors. Arch Phys Med Rehabil 2001; 82: 107-113.

3 Krause JS, Broderick L. Patterns of recurrent pressure ulcers after spinal cord injury: Identification of risk and protective factors 5 or more years after onset. Arch Phys Med Rehabil 2004; 85: 1257-1264.
4 Saladin LS, Krause JS, Adkins RH. Pressure ulcer prevalence and barriers to treatment after spinal cord injury: comparisons of 4 groups based on race-ethnicity. NeuroRehabilitation 2009; 24: 57-66.

5 Saunders LL, Krause JS. Personality and behavioral predictors of pressure ulcer history. Top Spinal Cord Inj Rehabil 2010; 16: 61-71.

6 Saunders LL, Krause JS, Peters BA, Reed KS. The relationship of pressure ulcers, race, and socioeconomic conditions after spinal cord injury. J Spinal Cord Med 2010; 33: 387-395.

7 Saunders LL, Krause JS, Acuna J. Association of race, socioeconomic status, and health care access with pressure ulcers after spinal cord injury. Arch Phys Med Rehabil 2012; 93: 972-977.

8 Chen Y, Devivo MJ, Jackson AB. Pressure ulcer prevalence in people with spinal cord injury: age-period-duration effects. Arch Phys Med Rehabil 2005; 86: 1208-1213.

9 DeJong G, Hsieh CH, Brown P, Smout RJ, Horn SD, Ballard P et al. Factors associated with pressure ulcer risk in spinal cord injury rehabilitation. Am J Phys Med Rehabil 2014; 93: 971-986.

10 Gelis A, Dupeyron A, Legros P, Benaïm C, Pelissier J, Fattal C. Pressure ulcer risk factors in persons with SCl: part I: acute and rehabilitation stages. Spinal Cord 2009; 47: 99-107.

11 Gelis A, Dupeyron A, Legros P, Benaïm C, Pelissier J, Fattal C. Pressure ulcer risk factors in persons with spinal cord injury part 2: the chronic stage. Spinal Cord 2009; 47: 651-661.

12 DiVita MA, Granger CV, Goldstein R, Niewczyk P, Freudenheim JL. Risk factors for development of new or worsened pressure ulcers among patients in inpatient rehabilitation facilities in the United States: data from the Uniform Data System for Medical Rehabilitation. PM R 2015; 7: 599-612.

13 Regan M, Teasell R, Wolfe D, Keast D, Mortenson WB, Aubut JA et al. A systematic review of therapeutic interventions for pressure ulcers after spinal cord injury. Arch Phys Med Rehabil 2009; 90: 213-231.

14 Marin J, Nixon J, Gorecki C. A systematic review of risk factors for the development and recurrence of pressure ulcers in people with spinal cord injuries. Spinal Cord 2013; 51: 522-527.

15 Groah SL, Schladen M, Pineda CG, Hsieh CH. Prevention of pressure ulcers among people with spinal cord injury: a systematic review. PM R 2015; 7: 613-636.

16 Byrne DW, Salzberg CA. Major risk factors for pressure ulcers in the spinal cord disabled: a literature review. Spinal Cord 1996; 34: 255-263.

17 Michel JM, Willebois S, Ribinik P, Barrois B, Colin D, Passadori Y. As of 2012, what are the key predictive risk factors for pressure ulcers? Developing French guidelines for clinical practice. Ann Phys Rehabil Med 2012; 55: 454-465.

18 Reddy M, Gill SS, Rochon PA. Preventing pressure ulcers: a systematic review. JAMA 2006; 296: 974-984.

19 Tung JY, Stead B, Mann W, Ba'Pham, Popovic MR. Assistive technologies for selfmanaged pressure ulcer prevention in spinal cord injury: a scoping review. J Rehabil Res Dev 2015; 52: 131-146.

20 Krause JS, Carter RE, Pickelsimer EE, Wilson D. A prospective study of health and risk of mortality after spinal cord injury. Arch Phys Med Rehabil 2008; 89: 1482-1491.

21 Krause JS. Factors associated with risk for subsequent injuries after the onset of traumatic spinal cord injury. Arch Phys Med Rehabil 2004; 85: 1503-1508.

22 Whiteneck GG, Brooks CA, Charlifue S, Gerhart KA, Mellick D, Overholser D et al. The Craig Handicap Assessment and Reporting Technique. Craig Hospital: Englewood, CO, USA, 1992

23 Krause JS, McArdle JJ, Pickelsimer E, Reed KS. A latent variable structural path model of health behaviors after spinal cord injury. J Spinal Cord Med 2009; 32: 162-174.

24 Krause JS. Secondary conditions and spinal cord injury: a model for prediction and prevention. Top Spinal Cord Inj Rehabil 1996; 2: 217-227.

25 Guihan M, Garber SL, Bombardier CH, Goldstein B, Holmes SA, Cao L. Predictors of pressure ulcer recurrence in veterans with spinal cord injury. J Spinal Cord Med 2008; 31: 551-559.

26 Krause JS, Saunders LL, DiPiro ND, Reed KS. Theoretical risk and prevention model for secondary health conditions and mortality: 15 years of research. Top Spinal Cord Inj Rehabil 2013; 19: 15-24. 